OPEN ACCESS

Edited by:

Tadej Avcin,

University Medical Centre Ljubljana,

Slovenia

Reviewed by:

loannis Parodis,

Karolinska Institutet (KI), Sweden

Sule Yavuz,

Istanbul Bilim University, Turkey

*Correspondence:

George Bertsias

gbertsias@uoc.gr

Specialty section:

This article was submitted to

Rheumatology,

a section of the journal

Frontiers in Medicine

Received: 04 March 2018

Accepted: 08 May 2018

Published: 29 May 2018

Citation:

Gergianaki I and Bertsias G (2018)

Systemic Lupus Erythematosus in

Primary Care: An Update and

Practical Messages for the General

Practitioner. Front. Med. 5:161

doi: 10.3389/fmed.2018.00161

\section{Systemic Lupus Erythematosus in Primary Care: An Update and Practical Messages for the General Practitioner}

\author{
Irini Gergianaki and George Bertsias* \\ Rheumatology, Clinical Immunology and Allergy, University of Crete Faculty of Medicine, Iraklio, Greece
}

Systemic Lupus Erythematosus (SLE) is a complex chronic autoimmune disease that manifests a wide range of organ involvement. Traditionally, the diagnosis and management of SLE is provided at secondary and tertiary centers to ensure prompt initiation of treatment, adequate control of flares and prevention of irreversible organ damage. Notwithstanding, the role of primary care in SLE is also emerging as there are still significant unmet needs such as the diagnostic delay at the community level and the high burden of therapy- and disease-related comorbidities. In the present review, we summarize practical messages for primary care physicians and general practitioners (GPS) concerning early diagnosis and proper referral of patients with SLE. In addition, we discuss the main comorbidities complicating the disease course and the recommended preventative measures, and we also provide an update on the role and current educational needs of GPs regarding the disease.

Keywords: autoimmune disease, epidemiology, diagnosis, primary care, community, comorbidities

\section{INTRODUCTION}

Systemic lupus erythematosus (SLE) is a complex autoimmune disease with chronic relapsing-remitting course and variable manifestations leading a spectrum from mild mucocutaneous to devastating, life-threatening illness $(1,2)$. The clinical profile of lupus is often challenging as the disease can be unpredictable, affecting various organs with variable degree of severity, and is complicated by accrual of organ damage and comorbidities. Traditionally, the diagnosis and management of SLE is provided at secondary and tertiary centers with experience in the disease, to ensure prompt initiation of treatment, early recognition and control of flare-ups, and optimization of medical care during the disease course (3).

Notwithstanding, the role of primary care in routine management of patients with SLE is also emerging. Thus, lupus is no longer considered to be a rare disease and at the community level, there is likely a considerable number of patients who remain undiagnosed or experience significant diagnostic delays (4). Further, the burden of SLE is increasing in a fragmented health care system $(5,6)$. To optimize patient referral and management, the American College of Rheumatology (ACR) developed relevant guidelines in 1999 (1), which recommend that general practitioners (GPs) should monitor patients with mild stable lupus and manage more severe forms of disease 
in close collaboration with a specialist. Despite progress, many GPs are concerned about not having sufficient knowledge or experience to tackle SLE (7) and thus, tend to overestimate the consequences that the disease can have for their patients (8). To this end, Lam et al. (2) have published a comprehensive review on lupus for primary care professionals.

The present review aims to provide a contemporary view of SLE at the population level, followed by practical messages to primary care physicians/GPs concerning the early diagnosis and proper referral to rheumatologists. We discuss the main comorbidities complicating the disease course and the recommended preventive measures. We conclude with an update on the role and current educational needs of primary care doctors regarding lupus.

\section{THE CHANGING LANDSCAPE OF SLE What Causes Lupus?}

According to the current paradigm, SLE may be triggered in a genetically-susceptible individual by exposure to certain environmental risk factors. Epigenetic modifications (9) mediate the effect of the environment on immunologic responses (10), eventually leading to an inflammatory, autoimmune, multisystemic disease characterized by autoantibody production and tissue injury (11).

Epidemiologic evidence suggests that increased risk of SLE is associated with exposure to crystalline silica, cigarette smoking, use of oral contraceptives and hormone replacement therapy, while there is an inverse association with alcohol intake (12). Less confirmed associations have been reported for exposure to solvents, pesticides, heavy metals and air pollutants, whereas data regarding other environmental factors or triggers such as ultraviolet light, infections, vaccinations, solvents, pesticides, mercury, obesity, and perinatal factors, are yet inconclusive (12).

\section{Is Lupus a Hereditable Disease?}

A recent study showed that lupus heritability (defined as the proportion of the phenotypic variance explained by genetic factors) is approximately $44 \%$, which is lower than previously reported estimates (up to 66\%) (13). The remaining risk may be driven by shared ("familial") (26\%) and non-shared environmental factors $(30 \%)(14,15)$.

\section{Trends in SLE Frequency}

SLE has long been perceived as a rare disease but most recent studies have disputed this tenet (16). Although reports on SLE occurrence are conflicting, the overall worldwide trend is increasing (17) in terms of both prevalence $(5,18)$ and incidence (19). An almost 3-fold increase in new cases that was reported during the previous decades (50's -90 's) was primarily attributed to better recognition of milder forms of the disease (19). SLE is more common in urban as compared to rural areas and there is circumstantial evidence that lifestyle and environmental factors may account for this difference $(20,21)$. In view of the significant variations across regions, ethnicities and races, it is of great importance for a GP to be informed about the epidemiology and burden of SLE in her/his population of interest.

\section{The Role of Ethnicity}

Numerous studies report increased frequency of SLE in nonwhite people (5- to 9-fold increased incidence and 2- to 3 -fold increased prevalence as compared to whites) and in certain ethnicities such as African-Caribbean and South/East Asians (22-28). Further, ethnicities such as Hispanics tend to present with more severe disease, higher activity and organ damage accumulation (19, 27, 29-31), as well as with more comorbidities (increased risk of cardiovascular events). Illustratively, the prevalence of lupus nephritis, one of the most severe disease manifestations, ranges from 20 to $30 \%$ of SLE patients in Europe (32) and in the US (33), to more than $60 \%$ in certain ethnicities such as Asians $(34,35)$.

\section{Gender Differences: SLE in Men Is Emerging}

A recent review by Rees et al. (5) confirms that females have much higher incidence than males. On average, SLE exhibits a female-to-male ratio ranging from 10-15:1 in adults to 3-5:1 in children (36). Notably, the time of disease onset, clinical manifestations, comorbidities and disease course differ considerably between male and female patients (37). For instance, male patients often have more abrupt onset (38) and manifest more severe disease due to nephritis and serositis, although these findings have not been confirmed by all studies $(39,40)$. Together, evidence suggests that males may comprise a subgroup of patients with distinct characteristics (41), and that SLE in males is on the rise (20).

\section{The Role of Age: SLE Appears Not Only in Young Adults}

SLE can develop at any age (40) and tends to start later in men (typically, 5th to 7 th decade of life) than in women (3rd to 7 th decade) (5). In many studies, the mean age of SLE onset ranges 35-45 years old, especially at community settings. Data from UK primary care using the Clinical Practice Research Datalink showed that the mean age of SLE diagnosis approximated 49 years in males and 48 years in females; accordingly, GPs should suspect SLE not only in women of younger ages and likewise, they should not disregard the possibility of SLE in people aged 50 or 60 years (42).

Childhood lupus refers to $10-20 \%$ of all SLE cases (43) and compared to adults, children present with more renal (odds ratio [OR] 1.55) and neurological (OR 1.64) involvement (4448). Similar to adults, Caucasian children tend to present with less severe disease as compared to other ethnicities (49-51). Late-onset lupus refers to cases with disease onset after the age of 50. In this group, SLE has more insidious presentations with less specific symptoms which might be a reason for being undiagnosed (52). Thus, late-onset lupus manifests less nephritis and less disease activity (53-55). Unfortunately, the outcome is poorer with increased mortality probably due to comorbid situations and frailty (40). 


\section{WHEN TO SUSPECT LUPUS IN PRIMARY CARE?}

SLE can affect any organ including the musculoskeletal, skin, hematologic, renal, neuropsychiatric, cardiovascular, and respiratory system. The following points could be helpful in understanding the disease evolution in real-world setting:

First, not all manifestations appear simultaneously and occasionally, a time interval of several months or years may exist between them. In most patients, constitutional (especially fatigue), mucocutaneous and musculoskeletal represent the earliest complaints (56). Thus, data from the UK primary care using the Clinical Practice Research Datalink showed that musculoskeletal symptoms were most frequently (58.6\%) recorded in the 5 year-period before SLE definitive diagnosis (42). Conversely, only few patients reported signs of active involvement of the kidneys (proteinuria or cellular casts) or other major organs (serositis, seizures, or psychosis) prior to SLE diagnosis (42). It should be noted, however, that no specific pattern of symptoms/organ involvement combinations exists in SLE and overall, a milder disease pattern may prevail at the community level as opposed to large referral centers (20). These data imply that GPs are most likely to suspect SLE in patients who present with milder symptoms from the skin and joints, and practically, since arthritis/arthralgia are the most common initial symptoms of the disease, every young woman with these symptoms should be evaluated for possible SLE (57). Notwithstanding, major organ disease such as nephritis can sometimes be the presenting manifestation of lupus, thus emphasizing the role of primary care physicians in identifying early signs of renal involvement with simple, inexpensive tools (e.g., urinalysis). This is particularly important considering the 2012 Systemic Lupus International Cooperating Clinics (SLICC) criteria which enable the classification of SLE patients based solely on biopsy-proven lupus nephritis and positive autoantibodies (58). Importantly, early effective immunosuppressive therapy can improve renal outcomes in such patients (59).

Next, increased healthcare utilization during the time preceding SLE diagnosis has been reported. The median number of GP consultations increased during the 5-year interval preceding SLE diagnosis, i.e., from median 1 in the $48-54$ months before diagnosis to 38 in the $0-12$ months before diagnosis (42). Interestingly, a study performed in 682 children and young patients (aged 10-24 years) with SLE confirmed that they had significantly more health care visits than controls in the year before diagnosis with most (39\%) visits occurring with primary care physicians (60). At 9-12 months prior to diagnosis, utilization of healthcare resources was almost 2 -fold increased. "Fever, unspecified" and "chest pain, unspecified" symptoms were associated with shorter time to diagnosis. Notably, many young individuals with SLE carry psychiatric diagnoses prior to being diagnosed with SLE, which was also associated with increased pre-diagnosis healthcare use (60). Conclusively, a high index of suspicion of lupus is very important and in real-world primary care practice, SLE should be suspected in any patient who presents with unexplained manifestations involving two or more systems (61).

\section{DIAGNOSTIC STEPS IN PATIENTS PRESENTING WITH FEATURES SUGGESTIVE OF SLE: WHICH SEROLOGICAL LABS ARE NEEDED AT PRIMARY CARE LEVEL?}

Lupus is the disease with the greater number of detectable antibodies [more than 100 (62)] even though only the wellknown anti-nuclear antibodies (ANA) are frequently used as screening test due to their high sensitivity (63-65). A systematic literature review and meta-regression confirmed the very high sensitivity of ANA for SLE (66). Accordingly, ANA at a titer 1:80 (by indirect immunofluorescence) has been introduced as an entry criterion for the new, under development SLE classification criteria (66). Nevertheless, $27 \%$ of a panel of international lupus experts felt comfortable to diagnose SLE even in the absence of positive ANA (67). Remarkably, ANA have been shown to predate the clinical onset of lupus and could be useful in primary care for the early recognition of the disease (68).

However, a major drawback of ANA is the low diagnostic specificity since positive test can be found in numerous other autoimmune diseases (autoimmune thyroiditis, autoimmune liver diseases and myasthenia among others) but also in healthy individuals especially at low titres (69-71). Unfortunately, in primary care, ANA is often overused as a screening test for various rheumatic illnesses including lupus. This is also the case in pediatric cases where it should not be ordered as a screening test for non-specific complaints such as musculoskeletal pain. In practical terms, ANA should be ordered only in cases of adults or children with signs and/or symptoms suggestive of SLE. By limiting ANA testing, GPs can avoid unnecessary referrals, reduce medical expenses and anxiety for the patient and her/his family (72). If ANA is negative, it could be repeated at subsequent time point only when there are new or worsening signs and symptoms pointing toward the diagnosis of SLE (73). Other specific autoantibodies are used to confirm SLE diagnosis. Specifically, anti-double strand DNA can be used for both diagnosis and evaluation of disease activity, and anti-Sm antibodies are highly specific for SLE (74).

\section{DIAGNOSIS VS. CLASSIFICATION OF SLE}

Diagnosis of SLE is still based on the strong clinical acumen of expert rheumatologists, since no diagnostic criteria have been validated so far (75). Both the 1997 ACR and the 2012 SLICC (58) classification criteria sets reflect the above-described picture of a multi-faceted disease, and although they have been established for epidemiological studies, they are often used in clinical routine to support the initial diagnostic thoughts $(63,76)$.

Relevant for the primary care setting is the observation that the SLICC 2012 criteria display overall higher sensitivity as compared with the ACR 1997 criteria, especially early in the disease (i.e., first 5 years: 89.3 vs. $76.0 \%$, respectively) (77). 
Notably, in about $22 \%$ of community-based lupus cases, clinical diagnosis preceded the ACR-based definition by at least 1 year. These data suggest that, at the population level, not all individuals diagnosed with SLE by an expert rheumatologist fulfill the classification criteria (20). To this end, a Steering Committee appointed jointly by the European League Against Rheumatism (EULAR) and the ACR have been working on a new set of SLE classification criteria, developing a weighted scoring system which possibly will be helpful for the early phases of the disease, at which stage the existing criteria underperform compared to clinical SLE diagnosis (63). Although presence of more than 3 criteria makes the diagnosis of SLE probable, the opposite may not be true (75). To this end, diagnostic criteria remain an unmet need for SLE which is difficult to attain: nearly $100 \%$ sensitivity and $100 \%$ specificity would be needed and they should apply universally, therefore reliable biomarkers are needed. As Larosa et al. report in an interesting review regarding the advances in classification and diagnostic criteria, it may be over-simplistic to dichotomize as "present" or "absent" a disease that may evolve $(78,79)$. Nonetheless, the practical message for the GP is that the classification criteria are useful as a reminder and guide for considering the diagnosis of SLE and having any possible cases referred to specialists for further assessment.

\section{THE CONCEPT OF PRECLINICAL LUPUS}

Current paradigm supports the notion that there is a progression from a phase of asymptomatic autoimmunity ("preclinical lupus") through initial symptoms of the disease (incomplete lupus erythematosus) to full-spectrum SLE (complete lupus erythematosus) which can be classified also with the classification criteria. This entity of "pre-lupus" would be of value to be recognized from a primary care physician as nearly $20 \%$ of such cases will progress into full-blown SLE (80). Moreover, the term "undifferentiated connective tissue disease" (UCTD) has been used to describe the existence of signs and symptoms consistent with SLE or other defined systemic autoimmune connective tissue disease but that do not yet fulfill the classification criteria (81). At present, we cannot accurately predict which patients will eventually develop the disease (82). Incomplete lupus erythematosus presents with fewer clinical manifestations than SLE, however patients can also accrue organ damage and early mortality (83). Common features include polyarthritis or hematological disorders and on average, patients are older than those with SLE and less likely to have ANA titers $\geq 1: 80(83,84)$.

\section{LUPUS MIMICKERS AND OVERLAP SYNDROMES}

Differential diagnosis is important in lupus diagnostics since many other autoimmune diseases present clinical similarities (including ANA positive tests) such as autoimmune hepatitis, dermatomyositis, inflammatory myopathies, juvenile idiopathic arthritis, primary biliary cirrhosis, rheumatoid arthritis, Sjögren's syndrome and systemic sclerosis (85). Lupus mimickers refer to a group of conditions that exhibit clinical and laboratory features resembling SLE and include infections, neoplasms and medications (85). The most frequent entity reported as a lupus mimicker is viral infection especially from parvo virus. Moreover, there are a number of overlap syndromes that combine SLE characteristics with features from other diseases including rheumatoid arthritis (also referred to as "rhupus"), polymyositis/dermatomyositis, systemic sclerosis and Sjögren's syndrome (86). In addition, the term mixed connective tissue disease (MCTD) is used to define a combination of clinical manifestations of SLE, cutaneous systemic sclerosis and polymyositis/dermatomyositis, in the presence of anti-U1-RNP antibodies. The main symptoms of this disorder include polyarthritis, hand edema, Raynaud's phenomenon, sclerodactyly, myositis and esophageal hypomobility, and studies have suggested a low frequency of evolution into another definite connective tissue disease (87).

\section{DRUG-INDUCED LUPUS AND OTHER LUPUS-LIKE CONDITIONS}

Drug-induced lupus refers to an autoimmune disorder that resembles SLE and is actually an idiosyncratic adverse effect of certain medications, particularly hydralazine, procainamide, isoniazid, minocycline, diltiazem and TNF inhibitors (88). Most cases appear after medium-to-long term exposure to the offending agent and tend to manifest arthralgias or arthritis, myalgia, fatigue, and serositis. The distinction from SLE is based on the history of drug exposure and the absence of specific lupus features and autoantibodies such as anti-dsDNA and Extractable Nuclear Antigen Antibodies (ENA) (89). Other organ-limited autoimmune diseases, especially autoimmune thyroid disease (90), as well as primary immunodeficiency syndromes (91), can present with mild lupus-like manifestations from the skin and joints.

\section{DOES EARLIER DIAGNOSIS OF SLE MATTER?}

Population-based screening for SLE is currently not advised. Although increasing awareness of SLE has reduced diagnostic delay, still the average time from symptom onset to diagnosis is approximately 2 years (92). Probably due to the lower suspicion, a longer time lag has been reported for children, males and late-onset disease (42). Patients with less than 6 months' delay may experience lower flare rates, less healthcare utilization and costs, as compared with those with at least 6 months' delay (93). Notably, for patients with major organ disease (nephritis, neurological), delay in prompt diagnosis and initiation of immunosuppressive therapy has been linked to adverse outcomes (94-96). Additionally, failure to achieve low disease activity in the first 6 months after diagnosis has been associated with early damage accrual $(95,97)$. Finally, in patients with early disease, all subscales of quality of life can be improved with proper therapy over a period of 2 years (98). 


\section{WHEN TO REFER A PATIENT WITH POSSIBLE LUPUS}

If the history and physical examination are not suggestive of clinically-overt disease and laboratory tests show only an isolated, low-titer positive ANA, the patient can be followed at primary care after education about warning signs and symptoms. At this point, patients warranting specialist follow-up include individuals with a family history of lupus or from high-risk ethnic descent. Co-existence of positive ANA and one or more other possible SLE features is the most frequent cause for rheumatology consultation in order to rule out SLE (75). A recent review showed that a reliable and validated tool to rate the urgency of referrals from a primary care doctor to a rheumatologist is not currently available (99).

\section{WHAT ARE THE CONCERNS/QUESTIONS OF PEOPLE WHO HAVE LUPUS?}

The principal concerns of lupus patients include fear of worsening so that they become dependent on others, of not being able to take care of their children, and of the possibility of transmitting SLE to their children (100). Non-adherence to recommended therapy is more common at the first stages because of the difficulty patients face in accepting a chronic disease that requires lifelong treatment (100). Interestingly, of the 10 top patient concerns, only two were common to the top 10 physician concerns and vice versa: most of what physicians rated higher, were rated lower by patients, suggesting the existence of communication gap (101). Another explanation could be the different perspectives and priorities of patients with SLE, especially the younger ones (102), such as the limitation of their capacities at physical and social level or achieving their personal goals. In this context, a GP may help to alleviate patients' concerns and improve their adherence to therapy (103).

\section{SEVERE FORMS OF SLE}

Lupus nephritis represents one of the severe complications of SLE, accounting for increased morbidity (including end-stage renal disease) and mortality $(59,104,105)$, therefore early suspicion at the primary care level is of paramount importance. Neuropsychiatric lupus is also an emerging severe lupus phenotype (20) and encompasses a wide range of neurologic and psychiatric manifestations of varying severity such as seizures, cognitive dysfunction, psychosis and depression $(106,107)$. Of note, seizure disorder is not rare and can sometimes be the presenting manifestation of SLE. Therefore, GPs should have a low threshold to evaluate and/or refer such cases for possible SLE, as this can result in prompt initiation of immunosuppressive treatment apart from anti-epileptic intervention (108).

\section{ANTIPHOSPHOLIPID SYNDROME (APS)}

APS is the association of thrombosis and/or pregnancy morbidity with antiphospholipid antibodies (aPL) (lupus anticoagulant [LA], anticardiolipin antibodies [aCL], and/or anti- $\beta_{2}$-glycoprotein-I antibodies $\left[\mathrm{a} \beta_{2} \mathrm{GPI}\right]$ ) and can occur as secondary disease in $15-20 \%$ of SLE patients (109). SLE patients with aPL have a higher prevalence of thrombosis, pregnancy morbidity, valve disease, thrombocytopenia, hemolytic anemia, renal lesions, and cognitive impairment; and higher tissue and organ damage $(109,110)$. At the primary care level, consecutive miscarriages and/or unexplained thrombotic event, especially in the absence of traditional risk factors, should raise the suspicion of APS (111).

\section{PREGNANCY IN LUPUS}

As SLE is frequently diagnosed during the childbearing years, reproductive health issues are relevant to everyday practice (112). Although fertility is generally preserved and the rate of live births ranges $85-90 \%$, still pregnancy is considered a high-risk situation for female SLE patients (113). Specifically, there is increased risk for disease flares and pregnancy-related complications such as preeclampsia (113). There is also increased risk for fetal morbidity, particularly preterm birth (relative risk [RR] 2.05) (114)], intrauterine growth restriction, and neonatal lupus. To this end, the EULAR has issued specific recommendations for the risk stratification and management of pregnancy in women with SLE (115). In this context, GPs may play an important role, especially at the pre-conception stage by assessing for exposure to any potentially harmful medications.

\section{SLE MULTI-MORBIDITY}

SLE is frequently burdened with a variety of comorbidities [cardiovascular disease, metabolic syndrome (116), malignancies (117-121), infections (122) and osteoporosis, among others] $(1,123-125)$. Comorbidities have an adverse impact on healthrelated quality of life (126), work productivity (127) and survival $(128,129)$ and lead to more complex management, increased hospitalizations and healthcare costs (130). Male patients have higher rates of cardiovascular disease/stroke and cancer. Conversely, female patients develop higher rates of infections and osteoporosis. Notably, patients at younger age groups are at the greatest risk for comorbid conditions compared with their healthy counterparts (123). Comorbidities can change over time in relation to patient age and use of medications, therefore their presence, severity and impact should be updated at regular intervals (131).

A recent meta-analysis revealed at least 2 -fold increased cardiovascular risk for SLE patients, with elderly patients having the highest absolute risk and young women presenting very high relative risks as compared with the general population (132). Traditional risk factors do not fully explain the increased risk and autoimmunity (anti-phospholipid antibodies, disease activity, and inflammation) has been implicated (124). To this end, SLE has been considered an independent risk factor for ischemic heart disease (133).

In terms of metabolic risk factors, hypertension may be as prevalent as $75 \%$ in various SLE cohorts (124). The prevalence of dyslipidemia ranges from $36 \%$ at diagnosis to $60 \%$ after 3 years. Numerous mechanisms are implicated in its pathogenesis, 
including antibodies against lipoprotein lipase as well as cytokines that affect the balance and content of lipoproteins (134). Prevalence of diabetes ranges from 2.7 to $7 \%$ and increases over time after diagnosis reaching up to $14 \%$ (135). Obesity (defined as body mass index [BMI] $>30 \mathrm{~kg} / \mathrm{m}^{2}$ ] is present in about one third of patients (136).

SLE patients have nearly 2 -fold increased frequency of atopic dermatitis (6.8 vs. $3.1 \%$ ) and asthma (10.6 vs. $7.6 \%$ ) as compared to controls (137). Further, the overall incidence rate of chronic obstructive pulmonary disease was 1.7-fold higher in SLE patients than controls (138).

Infections are an emerging problem for SLE patients. It is estimated that $14-52 \%$ of SLE hospitalizations are due to infections including pneumonia and opportunistic infections (i.e., pneumocystis pneumonia, herpes zoster, cytomegalovirus) (139).

Finally, the pooled risk ratio (RR) for all types of malignant disorders in patients with SLE has been estimated to 1.28 (117-121). This risk is related to the pathology of the underlying rheumatic disease including the inflammatory process, immunological abnormalities, and exposures such as smoking and viral infections (140). In particular, SLE has been associated with increased risk of non-Hodgkin lymphoma (OR 3.02), Hodgkin lymphoma (OR 2.43) and multiple myeloma (OR 2.57) (118). SLE also is a risk factor for cervical neoplasia (119). In contrast, there is a decreased risk of hormone-sensitive cancers such as breast and prostate (141).

Fibromyalgia is another frequent comorbidity (range 6-22\% of lupus patients) especially after the first 5 year since diagnosis. Its recognition is important for the optimal management of the disease $(142,143)$.

Regarding mental comorbidities, a meta-analysis revealed that the prevalence estimates of depression and anxiety were 30-39 and $40 \%$, respectively in SLE patients (144) which were higher than the general population and higher than other rheumatic diseases (144). The EULAR has issued recommendations for monitoring and treating comorbidities in SLE (131).

\section{PREVENTATIVE MEASURES IN PATIENTS WITH SLE}

The EULAR has highlighted the benefit of smoking cessation, weight control and physical exercise as adjuvant therapy in patients with SLE, especially those with increased cardiovascular risk (145).

\section{Smoking Cessation}

Smoking has been long implicated as a trigger factor for SLE onset, characteristically, described as "the fire behind the disease" (146-150). Strong associations have been recently supported between current smoking and more than 10 pack-years of smoking with SLE risk (hazard ratio [HR] 1.86) and positive antidsDNA autoantibodies (151). Notably, smoking cessation was shown to reduce such risk to that of non-smokers suggesting that this is a modifiable risk factor $(151,152)$. The impact of smoking on the course of SLE is not consistent across studies, however most findings suggest increased cutaneous manifestations, flares and organ damage scores (153) as well as worse therapeutic results (154) in smokers than in non-smokers.

\section{Weight Control}

Obesity may lead to decreased functional capacity, more fatigue, and increased risk of metabolic syndrome in lupus patients. Therefore, patients should be advised to lose excessive weight $(155,156)$. It is important to highlight that the negative impact of obesity occurs at a lower BMI than is often considered clinically as a problem, so addressing this preventable risk factor may improve long-term outcomes (157).

\section{Physical Activity and Healthy Lifestyle}

Given the increased cardiovascular risk in SLE, effective interventions are suggested to improve physical activity levels (158). Barriers such as joint pain, osteoporosis, neuropathy encourage sedentary lifestyle, a physical state that is not routinely addressed by physicians during follow up. In lupus patients, enhanced quality of life and better metabolic profile were reported in more physically active patients (155). Physical activity is safe in most autoimmune diseases including SLE. Aerobic exercise has been shown to increase exercise tolerance and improve baseline oxygen consumption. A diet rich in polyunsaturated fatty acids, avoiding a sedentary lifestyle and engaging exercise under supervision may be recommended for patients with stable SLE (153).

\section{Cancer Screening}

Due to the lack of studies comparing enhanced cancer screening in lupus patients, it is currently recommended that patients with SLE should adhere to general population guidelines, with potentially enhanced screening for cervical dysplasia/cancer, especially in those who have received highpotency immunosuppressive therapy such as cyclophosphamide.

\section{Immunizations}

Immunizations against pneumococus and influenza are recommended in SLE patients $(159,160)$. Live virus vaccines are contraindicated when patients are receiving immunosuppressive treatments (including prednisolone at a dose $>20 \mathrm{mg} /$ day), however, live attenuated vaccinations are permitted on a case-tocase basis. Vaccinations should generally be administered while the disease is under control (161). Patients with lupus who are as young as age 40 years could potentially benefit from herpes zoster vaccines (162). Moreover, available data suggest that HPV vaccines can be given safely, given the increased incidence of cervical abnormalities due to HPV in SLE, this vaccination should be offered (163).

\section{Preventing Treatment-Associated Comorbidities}

Glucocorticoids and antimalarial drugs are the mainstream in lupus management along with immunosuppressive or biologic drugs. Glucocorticoids are linked to adverse long-term consequences including organ damage accrual. Consequently, reduction and, when possible, complete withdrawal of 
glucocorticoids should be attempted (164). Emerging evidence suggests that, in chronic maintenance therapy of SLE, steroid dose should not exceed $5 \mathrm{mg}$ /day of prednisone equivalent.

On the contrary, data underscore favorable effects of prolonged treatment with antimalarials, not only on controlling disease activity but also on reducing damage accrual and mortality rates. Accordingly, current recommendations suggest that antimalarial drugs such as hydroxychloroquine should be considered in all SLE patients (165, 166). Hydroxychloroquine is generally safe and may be prescribed even during pregnancy and lactation. Caution is required for the early detection of retinopathy, a rare but serious complication of the prolonged use (167). Belimumab is the first biologic approved for the treatment of lupus inhibiting B-cell activity (168) and treated patients demonstrated significant clinical improvement with a concomitant reduction or discontinuation of glucocorticoids in $70.5 \%$ (169).

Adjunctive therapies should be considered to control comorbidity in lupus (166), a recommendation reflecting drugs such as anti-hypertensives, lipid-lowering agents, hypoglycemics, antiplatelet/anticoagulants, and bone-protecting agents (170). These treatments are safe and efficacious in SLE patients as in the general population, although there are very few controlled studies to support benefit on long-term outcomes (171). Notably, some of the aforementioned therapies may exhibit additional benefits in patients with SLE such as the antiproteinuric effects of renin-angiotensin axis inhibitors in lupus nephritis (172) and the use of antiplatelet agents for primary thromboprophylaxis in patients with positive antiphospholipid antibodies (173). Finally, there is weak evidence to support the use of complementary medicines in the management of the disease (170).

\section{THE IMPACT A GP COULD HAVE ON LUPUS CARE: BARRIERS AND EXPECTATIONS}

The challenge of a model of integrated lupus care should undoubtedly point toward optimization of patient consultation. In real-world terms, this is far from ideal since many lupus patients do not routinely consult a GP and importantly, many GPs do not feel comfortable to manage such a complex disease as lupus (7). Interestingly, GPs consider SLE to be a much more severe condition than rheumatologists (and patients) actually do (8). In an older study, GPs diagnosed correctly only $11 \%$ of SLE cases presented in written scenarios, much less than rheumatologists did (174). Urowitz et al. suggested that guidelines for patients with inactive disease should be modified to include at least co-management by the rheumatologist specialized physician (175).

Lack of knowledge or education of GPs at rheumatology departments during their training may contribute to this situation. GPs usually rely on textbooks or academic tertiary care studies which emphasize on severe SLE forms with scarce reliable evidence derived from their own setting. Accordingly, it would be helpful if education efforts had a more direct relevance to GP workforce to guide their clinical practice $(8,21)$. Although there have been efforts to establish screening strategies to identify undiagnosed cases of SLE in the community (29, 30, 176), further studies are generally required. As SLE patients consult their general practitioner more frequently with relevant clinical features during the 5-year period prior to diagnosis, opportunities emerge to reduce diagnostic delay in primary care (176).

"Every lupus patient should have a primary care physician, who should be in regular communication with the rheumatologist and vice versa" highlights Wallace (7) and nowadays, there is substantial progress in understanding and management of lupus patients from primary care doctors (177).

Due to the multi-organ nature of the disease, patients often have to face a fragmented care system as they need even more specialized care, especially in case of severe manifestations such as renal or neuropsychiatric disease. This situation, apart from causing patient discomfort, has been associated with negative outcomes (6). Unfortunately, there is a lack of high quality evidence for interdisciplinary specialty care in the management of lupus (178).

\section{CONCLUSION}

SLE is a systemic autoimmune disease that affects multiple organs. Inevitably, specialists from many disciplines often involved in the care of these patients, which however, can result in fragmented care. GPs need to deliver evidenceinformed, patient-centered care, while at the same time recognizing the fact that they are restricted by their training. To overcome uncertainties and difficulties in the clinical management of SLE patients, collaboration between specialists from different disciplines and different levels of care (primary, secondary, tertiary) is of paramount importance. Developing robust evidence, tools to support informed patient decisions, and multidisciplinary shared-care pathways may facilitate this process. In this regard, the role of GPs is critical in recognizing both milder and severe presentations of SLE, navigating patients and ameliorating the disease burden at the community level.

\section{AUTHOR CONTRIBUTIONS}

IG conceived and drafted the paper. GB supervised the work and edited the paper.

\section{ACKNOWLEDGMENTS}

IG is supported by the Pancretan Health Association. 


\section{REFERENCES}

1. Agmon-Levin N, Mosca M, Petri M, Shoenfeld Y. Systemic lupus erythematosus one disease or many? Autoimmu Rev. (2012) 11:593-5. doi: 10.1016/j.autrev.2011.10.020

2. Lam NC, Ghetu MV, Bieniek ML. Systemic lupus erythematosus: primary care approach to diagnosis and management. Am Family Physician (2016) 94:284-94.

3. Aljohani R, Gladman DD, Su J, Urowitz MB. Comparison of systemic lupus erythematosus (SLE) patients managed early after diagnosis in specialty versus community care clinics. Clin Rheumatol. (2017) 36:1773-8. doi: 10.1007/s10067-017-3713-7

4. Johnson AE, Gordon C, Hobbs FD, Bacon PA. Undiagnosed systemic lupus erythematosus in the community. Lancet (1996) 347:367-9. doi: 10.1016/S0140-6736(96)90539-5

5. Rees F, Doherty M, Grainge MJ, Lanyon P, Zhang W. The worldwide incidence and prevalence of systemic lupus erythematosus: a systematic review of epidemiological studies. Rheumatology (2017) 56:1945-61. doi: 10.1093/rheumatology/kex260

6. Walunas TL, Jackson KL, Chung AH, Mancera-Cuevas KA, Erickson DL, Ramsey-Goldman R, et al. Disease outcomes and care fragmentation among patients with systemic lupus erythematosus. Arthritis Care Res. (2017) 69:1369-76. doi: 10.1002/acr.23161

7. Wallace DJ. Improving the prognosis of SLE without prescribing lupus drugs and the primary care paradox. Lupus (2008) 17:91-2. doi: $10.1177 / 0961203307086267$

8. Arat S, Lenaerts JL, De Langhe E, Verschueren P, Moons P, Vandenberghe $\mathrm{J}$, et al. Illness representations of systemic lupus erythematosus and systemic sclerosis: a comparison of patients, their rheumatologists and their general practitioners. Lupus Sci Med. (2017) 4:e000232. doi: 10.1136/lupus-2017-000232

9. Hedrich CM. Epigenetics in SLE. Curr Rheumatol Rep. (2017) 19:58. doi: 10.1007/s11926-017-0685-1

10. Costenbader KH, Gay S, Alarcon-Riquelme ME, Iaccarino L, Doria A. Genes, epigenetic regulation and environmental factors: which is the most relevant in developing autoimmune diseases? Autoimmu Rev. (2012) 11:6049. doi: 10.1016/j.autrev.2011.10.022

11. Teruel M, Alarcon-Riquelme ME. The genetic basis of systemic lupus erythematosus: what are the risk factors and what have we learned. $J$ Autoimmu. (2016) 74:161-75. doi: 10.1016/j.jaut.2016.08.001

12. Parks CG, de Souza Espindola Santos A, Barbhaiya M, Costenbader KH. Understanding the role of environmental factors in the development of systemic lupus erythematosus. Best Pract Res Clin Rheumatol. (2017) 31:30620. doi: 10.1016/j.berh.2017.09.005

13. Kuo CF, Grainge MJ, Valdes AM, See LC, Luo SF, Yu KH, et al. Familial aggregation of systemic lupus erythematosus and coaggregation of autoimmune diseases in affected families. JAMA Intern Med. (2015) 175:1518-26. doi: 10.1001/jamainternmed.2015.3528

14. Lawrence JS, Martins CL, Drake GL. A family survey of lupus erythematosus. 1. Heritability. J Rheumatol. (1987) 14:913-21.

15. Yang J, Visscher PM, Wray NR. Sporadic cases are the norm for complex disease. Eur J Hum Genet. (2010) 18:1039-43. doi: 10.1038/ejhg.2009.177

16. Rees F, Doherty M, Grainge M, Davenport G, Lanyon P, Zhang $\mathrm{W}$. The incidence and prevalence of systemic lupus erythematosus in the UK, 1999-2012. Ann Rheum Dis. (2016) 75:136-41. doi: 10.1136/annrheumdis-2014-206334

17. Hill JC, Dunn KM, Lewis M, Mullis R, Main CJ, Foster NE, et al. A primary care back pain screening tool: identifying patient subgroups for initial treatment. Arthritis Rheum. (2008) 59:632-41. doi: 10.1002/art.23563

18. Leonhardt T. Family studies in systemic lupus erythematosus. Acta Med Scand. (1964) 176:SUPPL 416:1+.

19. Lewis MJ, Jawad AS. The effect of ethnicity and genetic ancestry on the epidemiology, clinical features and outcome of systemic lupus erythematosus. Rheumatology (2017) 56(suppl. 1):i67-77. doi: 10.1093/rheumatology/kew399

20. Gergianaki I, Fanouriakis A, Repa A, Tzanakakis M, Adamichou C, Pompieri $A$, et al. Epidemiology and burden of systemic lupus erythematosus in a Southern European population: data from the community-based lupus registry of Crete, Greece. Ann Rheum Dis. (2017) 76:1992-2000. doi: 10.1136/annrheumdis-2017-211206

21. Pons-Estel GJ, Saurit V, Alarcon GS, Hachuel L, Boggio G, Wojdyla D, et al. The impact of rural residency on the expression and outcome of systemic lupus erythematosus: data from a multiethnic Latin American cohort. Lupus (2012) 21:1397-404. doi: 10.1177/0961203312458465

22. Izmirly PM, Wan I, Sahl S, Buyon JP, Belmont HM, Salmon JE, et al. The incidence and prevalence of systemic lupus erythematosus in New York County (Manhattan), New York: the manhattan lupus surveillance program. Arthritis Rheum. (2017) 69:2006-17. doi: 10.1002/art.40192

23. Dall'Era M, Cisternas MG, Snipes K, Herrinton LJ, Gordon C, Helmick CG. The incidence and prevalence of systemic lupus erythematosus in San Francisco County, California: the California lupus surveillance project. Arthritis Rheum. (2017) 69:1996-2005. doi: 10.1002/art.40191

24. Lim SS, Bayakly AR, Helmick CG, Gordon C, Easley KA, Drenkard C. The incidence and prevalence of systemic lupus erythematosus, 20022004: the Georgia lupus registry. Arthritis Rheumatol. (2014) 66:357-68. doi: $10.1002 /$ art.38239

25. Somers EC, Marder W, Cagnoli P, Lewis EE, DeGuire P, Gordon C, et al. Population-based incidence and prevalence of systemic lupus erythematosus: the Michigan Lupus Epidemiology and Surveillance program. Arthritis Rheum. (2014) 66:369-78. doi: 10.1002/art.38238

26. Molokhia M, Hoggart C, Patrick AL, Shriver M, Parra E, Ye J, et al. Relation of risk of systemic lupus erythematosus to west African admixture in a Caribbean population. Hum Genet. (2003) 112:310-8. doi: 10.1007/s00439-002-0883-3

27. Lau CS, Yin G, Mok MY. Ethnic and geographical differences in systemic lupus erythematosus: an overview. Lupus (2006) 15:715-9. doi: $10.1177 / 0961203306072311$

28. Williams EM, Bruner L, Adkins A, Vrana C, Logan A, Kamen D, et al. I too, am America: a review of research on systemic lupus erythematosus in African-Americans. Lupus Sci Med. (2016) 3:e000144. doi: 10.1136/lupus-2015-000144

29. Ugarte-Gil MF, Pons-Estel GJ, Molineros J, Wojdyla D, McGwin G, Jr., Nath SK, et al. Disease features and outcomes in United States lupus patients of Hispanic origin and their Mestizo counterparts in Latin America: a commentary. Rheumatology (2016) 55:436-40. doi: 10.1093/rheumatology/kev280

30. Gonzalez LA, Toloza SM, Alarcon GS. Impact of race and ethnicity in the course and outcome of systemic lupus erythematosus. Rheum Dis Clin North Am. (2014) 40:433-54, vii-viii. doi: 10.1016/j.rdc.2014. 04.001

31. Gonzalez LA, Toloza SM, McGwin G Jr, Alarcon GS. Ethnicity in systemic lupus erythematosus (SLE): its influence on susceptibility and outcomes. Lupus (2013) 22:1214-24. doi: 10.1177/09612033135 02571

32. Cervera R, Khamashta MA. Epidemiology of systemic lupus erythematosus at the change of the millennium: lessons from the Euro-Lupus and the LUMINA projects. Lupus (2006) 15:1-2. doi: 10.1191/0961203306lu 2269ed

33. Feldman CH, Hiraki LT, Liu J, Fischer MA, Solomon DH, Alarcon GS, et al. Epidemiology and sociodemographics of systemic lupus erythematosus and lupus nephritis among US adults with Medicaid coverage, 2000-2004. Arthritis Rheum. (2013) 65:753-63. doi: 10.1002/art.37795

34. Fernandez M, Alarcon GS, Calvo-Alen J, Andrade R, McGwin G Jr, Vila LM, et al. A multiethnic, multicenter cohort of patients with systemic lupus erythematosus (SLE) as a model for the study of ethnic disparities in SLE. Arthritis Rheum. (2007) 57:576-84. doi: 10.1002/art.22672

35. Wang F, Wang CL, Tan CT, Manivasagar M. Systemic lupus erythematosus in Malaysia: a study of 539 patients and comparison of prevalence and disease expression in different racial and gender groups. Lupus (1997) 6:248-53. doi: $10.1177 / 096120339700600306$

36. Cattalini M, Soliani M, Caparello MC, Cimaz R. Sex differences in pediatric rheumatology. Clin Rev Allergy Immunol. (2017). doi: 10.1007/s12016-017-8642-3. [Epub ahead of print].

37. Tedeschi SK, Bermas B, Costenbader KH. Sexual disparities in the incidence and course of SLE and RA. Clin Immunol. (2013) 149:211-8. doi: 10.1016/j.clim.2013.03.003 
38. Arbuckle MR, James JA, Dennis GJ, Rubertone MV, McClain MT, Kim XR, et al. Rapid clinical progression to diagnosis among AfricanAmerican men with systemic lupus erythematosus. Lupus (2003) 12:99-106. doi: 10.1191/0961203303lu334oa

39. Krasselt M, Baerwald C. Sex, symptom severity, and quality of life in rheumatology. Clin Rev Allergy Immunol. (2017). doi: 10.1007/s12016-017-8631-6. [Epub ahead of print].

40. Pons-Estel GJ, Ugarte-Gil MF, Alarcon GS. Epidemiology of systemic lupus erythematosus. Expert Rev Clin immunology (2017) 13:799-814. doi: 10.1080/1744666X.2017.1327352

41. Lu LJ, Wallace DJ, Ishimori ML, Scofield RH, Weisman MH. Review: male systemic lupus erythematosus: a review of sex disparities in this disease. Lupus (2010) 19:119-29. doi: 10.1177/0961203309350755

42. Nightingale AL, Davidson JE, Molta CT, Kan HJ, McHugh NJ. Presentation of SLE in UK primary care using the Clinical Practice Research Datalink. Lupus Sci Med. (2017) 4:e00172. doi: 10.1136/lupus-2016-000172

43. Kamphuis S, Silverman ED. Prevalence and burden of pediatric-onset systemic lupus erythematosus. Nat Rev Rheumatol. (2010) 6:538-46. doi: $10.1038 /$ nrrheum.2010.121

44. Tucker LB, Uribe AG, Fernandez M, Vila LM, McGwin G, Apte M, et al. Adolescent onset of lupus results in more aggressive disease and worse outcomes: results of a nested matched case-control study within LUMINA, a multiethnic US cohort (LUMINA LVII). Lupus (2008) 17:31422. doi: 10.1177/0961203307087875

45. Wu CY, Li CF, Wu QJ, Xu JH, Jiang LD, Gong L, et al. Chinese systemic lupus erythematosus treatment and research group registry IX: clinical features and survival of childhood-onset systemic lupus erythematosus in China. Chin Med J. (2017) 130:1276-82. doi: 10.4103/0366-6999.206346

46. Hoffman IE, Lauwerys BR, De Keyser F, Huizinga TW, Isenberg D, Cebecauer L, et al. Juvenile-onset systemic lupus erythematosus: different clinical and serological pattern than adult-onset systemic lupus erythematosus. Ann Rheum Dis. (2009) 68:412-5. doi: 10.1136/ard.2008.094813

47. Hiraki LT, Benseler SM, Tyrrell PN, Hebert D, Harvey E, Silverman ED. Clinical and laboratory characteristics and long-term outcome of pediatric systemic lupus erythematosus: a longitudinal study. J Pediatr. (2008) 152:550-6. doi: 10.1016/j.jpeds.2007.09.019

48. Brunner HI, Gladman DD, Ibanez D, Urowitz MD, Silverman ED. Difference in disease features between childhood-onset and adult-onset systemic lupus erythematosus. Arthritis Rheum. (2008) 58:556-62. doi: 10.1002/art.23204

49. Levy DM, Peschken CA, Tucker LB, Chedeville G, Huber AM, Pope JE, et al. Influence of ethnicity on childhood-onset systemic lupus erythematosus: results from a multiethnic multicenter Canadian cohort. Arthritis Care Res. (2013) 65:152-60. doi: 10.1002/acr.21779

50. Ramirez Gomez LA, Uribe Uribe O, Osio Uribe O, Grisales Romero H, Cardiel MH, Wojdyla D, et al. Childhood systemic lupus erythematosus in Latin America. The GLADEL experience in 230 children. Lupus (2008) 17:596-604. doi: 10.1177/0961203307088006

51. Al-Mayouf SM, AlAmeer A, Alfattani A, Alsonbul A. Outcome of childhood lupus nephritis in Saudi children. Saudi J Kidney Dis Transpl. (2017) 28:1015-20. doi: 10.4103/1319-2442.215142

52. Rovensky J, Tuchynova A. Systemic lupus erythematosus in the elderly. Autoimmu Rev. (2008) 7:235-9. doi: 10.1016/j.autrev.2007. 11.014

53. Stefanidou S, Gerodimos C, Benos A, Galanopoulou V, Chatziyannis I, Kanakoudi F, et al. Clinical expression and course in patients with late onset systemic lupus erythematosus. Hippokratia (2013) 17:153-6.

54. Sohn IW, Joo YB, Won S, Bae SC. Late-onset systemic lupus erythematosus: Is it "mild lupus"? Lupus (2018) 27:235-42. doi: 10.1177/09612033177 16789

55. Sassi RH, Hendler JV, Piccoli GF, Gasparin AA, da Silva Chakr RM, Brenol JC, et al. Age of onset influences on clinical and laboratory profile of patients with systemic lupus erythematosus. Clin Rheumatol. (2017) 36:8995. doi: 10.1007/s10067-016-3478-4

56. Heinlen LD, McClain MT, Merrill J, Akbarali YW, Edgerton CC, Harley JB, et al. Clinical criteria for systemic lupus erythematosus precede diagnosis, and associated autoantibodies are present before clinical symptoms. Arthritis Rheum. (2007) 56:2344-51. doi: 10.1002/art.22665
57. Ozbek S, Sert M, Paydas S, Soy M. Delay in the diagnosis of SLE: the importance of arthritis/arthralgia as the initial symptom. Acta Med Okayama (2003) 57:187-90. doi: 10.18926/AMO/32807

58. Petri M, Orbai AM, Alarcon GS, Gordon C, Merrill JT, Fortin PR, et al. Derivation and validation of the Systemic Lupus International Collaborating Clinics classification criteria for systemic lupus erythematosus. Arthritis Rheum. (2012) 64:2677-86. doi: 10.1002/art.34473

59. Almaani S, Meara A, Rovin BH. Update on lupus nephritis. Clin J Am Soc Nephrol. (2017) 12:825-35. doi: 10.2215/CJN.05780616

60. Chang JC, Mandell DS, Knight AM. High health care utilization preceding diagnosis of systemic lupus erythematosus in youth. Arthritis Care Res. (2017). doi: 10.1002/acr.23485. [Epub ahead of print]

61. Pramanik B. Diagnosis of systemic lupus erythematosus in an unusual presentation: what a primary care physician should know. Curr Rheumatol Rev. (2014) 10:81-6. doi: 10.2174/1573397111999150128103237

62. Sherer Y, Gorstein A, Fritzler MJ, Shoenfeld Y. Autoantibody explosion in systemic lupus erythematosus: more than 100 different antibodies found in SLE patients. Semin Arthritis Rheum. (2004) 34:501-37. doi: 10.1016/j.semarthrit.2004.07.002

63. Tedeschi SK, Johnson SR, Boumpas D, Daikh D, Dorner T, Jayne D, et al. Developing and refining new candidate criteria for systemic lupus erythematosus classification: an international collaboration. Arthritis Care Res. (2018) 70:571-81. doi: 10.1002/acr.23317

64. Olsen NJ, Karp DR. Autoantibodies and SLE: the threshold for disease. Nat Rev Rheumatol. (2014) 10:181-6. doi: 10.1038/nrrheum.2013.184

65. Slater CA, Davis RB, Shmerling RH. Antinuclear antibody testing. A study of clinical utility. Arch Intern Med. (1996) 156:1421-5. doi: 10.1001/archinte.1996.00440120079007

66. Leuchten N, Hoyer A, Brinks R, Schoels M, Schneider M, Smolen J, et al. Performance of antinuclear antibodies for classifying systemic lupus erythematosus: a systematic literature review and meta-regression of diagnostic data. Arthritis Care Res. (2018) 70:428-38. doi: 10.1002/acr.23292

67. Schmajuk G, Hoyer BF, Aringer M, Johnson SR, Daikh DI, Dorner $\mathrm{T}$, et al. Multi-center delphi exercise reveals important key items for classifying systemic lupus erythematosus. Arthritis Care Res. (2017). doi: 10.1002/acr.23503. [Epub ahead of print].

68. Eriksson C, Kokkonen H, Johansson M, Hallmans G, Wadell G, Rantapaa-Dahlqvist S. Autoantibodies predate the onset of systemic lupus erythematosus in northern Sweden. Arthritis Res Ther. (2011) 13:R30. doi: $10.1186 / \operatorname{ar} 3258$

69. Tan EM, Feltkamp TE, Smolen JS, Butcher B, Dawkins R, Fritzler MJ, et al. Range of antinuclear antibodies in "healthy" individuals. Arthritis Rheum. (1997) 40:1601-11. doi: 10.1002/art.1780400909

70. Wandstrat AE, Carr-Johnson F, Branch V, Gray H, Fairhurst AM, Reimold A, et al. Autoantibody profiling to identify individuals at risk for systemic lupus erythematosus. J Autoimmu. (2006) 27:153-60. doi: 10.1016/j.jaut.2006.09.001

71. de Vlam K, De Keyser F, Verbruggen G, Vandenbossche M, Vanneuville B, D'Haese D, et al. Detection and identification of antinuclear autoantibodies in the serum of normal blood donors. Clin Exp Rheumatol. (1993) 11:393-7.

72. Malleson PN, Mackinnon MJ, Sailer-Hoeck M, Spencer CH. Review for the generalist: The antinuclear antibody test in children - When to use it and what to do with a positive titer. Pediatr Rheumatol Online J. (2010) 8:27. doi: 10.1186/1546-0096-8-27

73. Gordon C, Amissah-Arthur MB, Gayed M, Brown S, Bruce IN, D’Cruz D, et al. The British Society for Rheumatology guideline for the management of systemic lupus erythematosus in adults. Rheumatology (2018) 57:e1-45. doi: 10.1093/rheumatology/kex286

74. Arroyo-Avila M, Santiago-Casas Y, McGwin G Jr, Cantor RS, Petri M, Ramsey-Goldman R, et al. Clinical associations of anti-Smith antibodies in PROFILE: a multi-ethnic lupus cohort. Clin Rheumatol. (2015) 34:1217-23. doi: 10.1007/s10067-015-2941-y

75. Bertsias GK, Pamfil C, Fanouriakis A, Boumpas DT. Diagnostic criteria for systemic lupus erythematosus: has the time come? Nat Rev Rheumatol. (2013) 9:687-94. doi: 10.1038/nrrheum.2013.103

76. Aringer M, Dorner T, Leuchten N, Johnson SR. Toward new criteria for systemic lupus erythematosus-a standpoint. Lupus (2016) 25:805-11. doi: $10.1177 / 0961203316644338$ 
77. Ines L, Silva C, Galindo M, Lopez-Longo FJ, Terroso G, Romao VC, et al. Classification of systemic lupus erythematosus: systemic lupus international collaborating clinics versus American College of rheumatology criteria. A comparative study of 2,055 patients from a real-life, International systemic lupus erythematosus cohort. Arthritis Care Res. (2015) 67:1180-5. doi: 10.1002/acr.22539

78. Larosa M, Iaccarino L, Gatto M, Punzi L, Doria A. Advances in the diagnosis and classification of systemic lupus erythematosus. Expert Rev Clin Immunol. (2016) 12:1309-20. doi: 10.1080/1744666X.2016.1206470

79. June RR, Aggarwal R. The use and abuse of diagnostic/classification criteria. Best Pract Res Clin Rheumatol. (2014) 28:921-34. doi: 10.1016/j.berh.2015.04.004

80. Al Daabil M, Massarotti EM, Fine A, Tsao H, Ho P, Schur PH, et al. Development of SLE among "potential SLE" patients seen in consultation: long-term follow-up. Int J Clin Pract. (2014) 68:1508-13. doi: $10.1111 /$ ijcp. 12466

81. Mosca M, Tani C, Carli L, Bombardieri S. Undifferentiated CTD: a wide spectrum of autoimmune diseases. Best Pract Res Clin Rheumatol. (2012) 26:73-7. doi: 10.1016/j.berh.2012.01.005

82. Doria A, Zen M, Canova M, Bettio S, Bassi N, Nalotto L, et al. SLE diagnosis and treatment: when early is early. Autoimmu Rev. (2010) 10:5560. doi: 10.1016/j.autrev.2010.08.014

83. Bourn R, James JA. Preclinical lupus. Curr Opin Rheumatol. (2015) 27:433-9. doi: 10.1097/BOR.0000000000000199

84. Aberle T, Bourn RL, Munroe ME, Chen H, Roberts VC, Guthridge JM, et al. Clinical and serologic features in patients with incomplete lupus classification versus systemic lupus erythematosus patients and controls. Arthritis Care Res. (2017) 69:1780-8. doi: 10.1002/acr.23201

85. Calixto OJ, Franco JS, Anaya JM. Lupus mimickers. Autoimmu Rev. (2014) 13:865-72. doi: 10.1016/j.autrev.2014.05.002

86. Iaccarino L, Gatto M, Bettio S, Caso F, Rampudda M, Zen M, et al. Overlap connective tissue disease syndromes. Autoimmu Rev. (2013) 12:363-73. doi: 10.1016/j.autrev.2012.06.004

87. Ferucci ED, Johnston JM, Gordon C, Helmick CG, Lim SS. Prevalence of mixed connective tissue disease in a population-based registry of American Indian/Alaska Native People in 2007. Arthritis Care Res. (2017) 69:1271-5. doi: 10.1002/acr.23135

88. Ho CH, Chauhan K. Lupus Erythematosus, Drug-Induced. StatPearls. Treasure Island, FL: StatPearls Publishing LLC (2018).

89. Rubin RL. Drug-induced lupus. Expert Opin Drug Saf. (2015) 14:361-78. doi: 10.1517/14740338.2015.995089

90. Sahin G, Korkmaz C, Isiksoy S, Yalcin AU. Autoimmune hypothyroidism and lupus-like syndrome. Rheumatol Int. (2010) 30:519-21. doi: 10.1007/s00296-009-0954-Z

91. Schmidt RE, Grimbacher B, Witte T. Autoimmunity and primary immunodeficiency: two sides of the same coin? Nat Rev Rheumatol. (2017) 14:7-18. doi: 10.1038/nrrheum.2017.198

92. Feng X, Zou Y, Pan W, Wang X, Wu M, Zhang M, et al. Associations of clinical features and prognosis with age at disease onset in patients with systemic lupus erythematosus. Lupus (2014) 23:327-34. doi: 10.1177/0961203313513508

93. Oglesby A, Korves C, Laliberte F, Dennis G, Rao S, Suthoff ED, et al. Impact of early versus late systemic lupus erythematosus diagnosis on clinical and economic outcomes. Appl Health Econ Health Policy (2014) 12:179-90. doi: 10.1007/s40258-014-0085-x

94. Esdaile JM, Mackenzie T, Barre P, Danoff D, Osterland CK, Somerville P, et al. Can experienced clinicians predict the outcome of lupus nephritis? Lupus (1992) 1:205-14. doi: 10.1177/096120339200100403

95. Faurschou M, Dreyer L, Kamper AL, Starklint H, Jacobsen S. Long-term mortality and renal outcome in a cohort of 100 patients with lupus nephritis. Arthritis Care Res. (2010) 62:873-80. doi: 10.1002/acr.20116

96. Lu X, Gu Y, Wang Y, Chen S, Ye S. Prognostic factors of lupus myelopathy. Lupus (2008) 17:323-8. doi: 10.1177/0961203307088005

97. Piga M, Floris A, Cappellazzo G, Chessa E, Congia M, Mathieu A, et al. Failure to achieve lupus low disease activity state (LLDAS) six months after diagnosis is associated with early damage accrual in Caucasian patients with systemic lupus erythematosus. Arthritis Res Ther. (2017) 19:247. doi: 10.1186/s13075-017-1451-5
98. Urowitz M, Gladman DD, Ibanez D, Sanchez-Guerrero J, Bae SC, Gordon C, et al. Changes in quality of life in the first 5 years of disease in a multicenter cohort of patients with systemic lupus erythematosus. Arthritis Care Res. (2014) 66:1374-9. doi: 10.1002/acr.22299

99. Fitzgerald A, de Coster C, McMillan S, Naden R, Armstrong F, Barber A, et al. Relative urgency for referral from primary care to rheumatologists: the Priority Referral Score. Arthritis Care Res. (2011) 63:231-9. doi: 10.1002/acr.20366

100. Farinha F, Freitas F, Agueda A, Cunha I, Barcelos A. Concerns of patients with systemic lupus erythematosus and adherence to therapy - a qualitative study. Patient Prefer Adher. (2017) 11:1213-9. doi: 10.2147/PPA.S137544

101. Golder V, Ooi JJY, Antony AS, Ko T, Morton S, Kandane-Rathnayake $\mathrm{R}$, et al. Discordance of patient and physician health status concerns in systemic lupus erythematosus. Lupus (2018) 27:501-6. doi: $10.1177 / 0961203317722412$

102. Parsons S, Thomson W, Cresswell K, Starling B, McDonagh JE, Barbara Ansell National Network for Adolescent R. What do young people with rheumatic disease believe to be important to research about their condition? A UK-wide study. Pediatr Rheumatol Online J. (2017) 15:53. doi: 10.1186/s12969-017-0181-1

103. Jolly M, Galicier L, Aumaitre O, Frances C, Le Guern V, Liote F, et al. Quality of life in systemic lupus erythematosus: description in a cohort of French patients and association with blood hydroxychloroquine levels. Lupus (2016) 25:735-40. doi: 10.1177/0961203315627200

104. Mok CC. Towards new avenues in the management of lupus glomerulonephritis. Nat Rev Rheumatol. (2016) 12:221-34. doi: 10.1038/nrrheum.2015.174

105. Norby GE, Mjoen G, Bjorneklett R, Vikse BE, Holdaas H, Svarstad E, et al. Outcome in biopsy-proven Lupus nephritis: evaluation of biopsies from the Norwegian Kidney Biopsy Registry. Lupus (2017) 26:881-5. doi: 10.1177/0961203316686700

106. Kivity S, Agmon-Levin N, Zandman-Goddard G, Chapman J, Shoenfeld Y. Neuropsychiatric lupus: a mosaic of clinical presentations. BMC Med. (2015) 13:43. doi: 10.1186/s12916-015-0269-8

107. Brey RL, Holliday SL, Saklad AR, Navarrete MG, HermosilloRomo D, Stallworth CL, et al. Neuropsychiatric syndromes in lupus: prevalence using standardized definitions. Neurology (2002) 58:1214-20. doi: 10.1212/WNL.58.8.1214

108. Watad A, Tiosano S, Bragazzi NL, Brigo F, Comaneshter D, Cohen AD, et al. Epilepsy among Systemic Lupus Erythematosus Patients: insights from a Large Database Analysis. Neuroepidemiology (2018) 50:1-6. doi: 10.1159/000485136

109. Unlu O, Zuily S, Erkan D. The clinical significance of antiphospholipid antibodies in systemic lupus erythematosus. Eur J Rheumatol. (2016) 3:7584. doi: 10.5152/eurjrheum.2015.0085

110. Cervera R, Piette JC, Font J, Khamashta MA, Shoenfeld Y, Camps MT, et al. Antiphospholipid syndrome: clinical and immunologic manifestations and patterns of disease expression in a cohort of 1,000 patients. Arthritis Rheum. (2002) 46:1019-27. doi: 10.1002/art.10187

111. Cavazzana I, Andreoli L, Limper M, Franceschini F, Tincani A. Update on antiphospholipid syndrome: ten topics in 2017. Curr Rheumatol Rep. (2018) 20:15. doi: 10.1007/s11926-018-0718-4

112. Clowse ME, Chakravarty E, Costenbader KH, Chambers C, Michaud K. Effects of infertility, pregnancy loss, and patient concerns on family size of women with rheumatoid arthritis and systemic lupus erythematosus. Arthritis Care Res. (2012) 64:668-74. doi: 10.1002/acr.21593

113. Lateef A, Petri M. Systemic lupus erythematosus and pregnancy. Rheum Dis Clin North Am. (2017) 43:215-26. doi: 10.1016/j.rdc.2016.12.009

114. Wei S, Lai K, Yang Z, Zeng K. Systemic lupus erythematosus and risk of preterm birth: a systematic review and meta-analysis of observational studies. Lupus (2017) 26:563-71. doi: 10.1177/0961203316 686704

115. Andreoli L, Bertsias GK, Agmon-Levin N, Brown S, Cervera R, Costedoat-Chalumeau N, et al. EULAR recommendations for women's health and the management of family planning, assisted reproduction, pregnancy and menopause in patients with systemic lupus erythematosus and/or antiphospholipid syndrome. Ann Rheum Dis (2017) 76:476-85. doi: 10.1136/annrheumdis-2016-209770 
116. Parker B, Bruce I. SLE and metabolic syndrome. Lupus (2013) 22:1259-66. doi: 10.1177/0961203313502570

117. Goobie GC, Bernatsky S, Ramsey-Goldman R, Clarke AE. Malignancies in systemic lupus erythematosus: a 2015 update. Curr Opin Rheumatol. (2015) 27:454-60. doi: 10.1097/BOR.0000000000000202

118. Azrielant S, Tiosano S, Watad A, Mahroum N, Whitby A, Comaneshter D, et al. Correlation between systemic lupus erythematosus and malignancies: a cross-sectional population-based study. Immunol Res. (2017) 65:464-9. doi: $10.1007 / \mathrm{s} 12026-016-8885-8$

119. Wadstrom H, Arkema EV, Sjowall C, Askling J, Simard JF. Cervical neoplasia in systemic lupus erythematosus: a nationwide study. Rheumatology (2017) 56:613-9. doi: 10.1093/rheumatology/kew459

120. Wu Y, Hou Q. Systemic lupus erythematous increased lung cancer risk: evidence from a meta-analysis. J Cancer Res Ther. (2016) 12:721-4. doi: 10.4103/0973-1482.172115

121. Cao L, Tong H, Xu G, Liu P, Meng H, Wang J, et al. Systemic lupus erythematous and malignancy risk: a meta-analysis. PLoS ONE (2015) 10:e0122964. doi: 10.1371/journal.pone.0122964

122. Tektonidou MG, Wang Z, Dasgupta A, Ward MM. Burden of serious infections in adults with systemic lupus erythematosus: a National population-based study, 1996-2011. Arthritis Care Res. (2015) 67:1078-85. doi: 10.1002/acr.22575

123. Rees F, Doherty M, Grainge M, Lanyon P, Davenport G, Zhang W. Burden of comorbidity in systemic lupus erythematosus in the UK, 1999-2012. Arthritis Care Res. (2016) 68:819-27. doi: 10.1002/acr.22751

124. Gonzalez LA, Alarcon GS. The evolving concept of SLE comorbidities. Expert Rev Clin Immunol. (2017) 13:753-68. doi: 10.1080/1744666X.2017.1327353

125. Thong B, Olsen NJ. Systemic lupus erythematosus diagnosis and management. Rheumatology (2017) 56 (suppl. 1):i3-13. doi: 10.1093/rheumatology/kew401

126. Alarcon GS, McGwin G Jr, Uribe A, Friedman AW, Roseman JM, Fessler BJ, et al. Systemic lupus erythematosus in a multiethnic lupus cohort (LUMINA). XVII. Predictors of self-reported health-related quality of life early in the disease course. Arthritis Rheum. (2004) 51:465-74. doi: 10.1002/art.20409

127. Baker K, Pope J, Fortin P, Silverman E, Peschken C, 1000 Faces of Lupus Investigators, et al. Work disability in systemic lupus erythematosus is prevalent and associated with socio-demographic and disease related factors. Lupus (2009) 18:1281-8. doi: 10.1177/0961203309345784

128. Jonsen A, Clarke AE, Joseph L, Belisle P, Bernatsky S, Nived O, et al. Association of the Charlson comorbidity index with mortality in systemic lupus erythematosus. Arthritis Care Res. (2011) 63:1233-7. doi: 10.1002/acr.20506

129. Ward MM, Pajevic S, Dreyfuss J, Malley JD. Short-term prediction of mortality in patients with systemic lupus erythematosus: classification of outcomes using random forests. Arthritis Rheum. (2006) 55:74-80. doi: 10.1002/art.21695

130. Yang Y, Thumboo J, Earnest A, Yong SL, Fong KY. The effect of comorbidity on hospital mortality in patients with SLE from an Asian tertiary hospital. Lupus (2014) 23:714-20. doi: 10.1177/0961203314522340

131. Mosca M, Tani C, Aringer M, Bombardieri S, Boumpas D, Cervera R, et al. Development of quality indicators to evaluate the monitoring of SLE patients in routine clinical practice. Autoimmu Rev. (2011) 10:383-8. doi: 10.1016/j.autrev.2010.12.008

132. Schoenfeld SR, Kasturi S, Costenbader KH. The epidemiology of atherosclerotic cardiovascular disease among patients with SLE: a systematic review. Semin Arthritis Rheum. (2013) 43:77-95. doi: 10.1016/j.semarthrit.2012.12.002

133. Watad A, Abu Much A, Bracco D, Mahroum N, Comaneshter D, Cohen $\mathrm{AD}$, et al. Association between ischemic heart disease and systemic lupus erythematosus-a large case-control study. Immunol Res. (2017) 65:459-63. doi: $10.1007 /$ s12026-016-8884-9

134. Tselios K, Koumaras C, Gladman DD, Urowitz MB. Dyslipidemia in systemic lupus erythematosus: just another comorbidity? Semin Arthritis Rheum. (2016) 45:604-10. doi: 10.1016/j.semarthrit.2015.10.010

135. Urowitz MB, Gladman D, Ibanez D, Fortin P, Sanchez-Guerrero J, Bae S, et al. Accumulation of coronary artery disease risk factors over three years: data from an international inception cohort. Arthritis Rheum. (2008) 59:176-80. doi: 10.1002/art.23353

136. Katz P, Gregorich S, Yazdany J, Trupin L, Julian L, Yelin E, et al. Obesity and its measurement in a community-based sample of women with systemic lupus erythematosus. Arthritis Care Res. (2011) 63:261-8. doi: 10.1002/acr.20343

137. Hsiao YP, Tsai JD, Muo CH, Tsai CH, Sung FC, Liao YT, et al. Atopic diseases and systemic lupus erythematosus: an epidemiological study of the risks and correlations. Int J Environ Res Public Health (2014) 11:8112-22. doi: 10.3390/ijerph110808112

138. Shen TC, Lin CL, Chen CH, Tu CY, Hsia TC, Shih CM, et al. Increased risk of chronic obstructive pulmonary disease in patients with systemic lupus erythematosus: a population-based cohort study. PLoS ONE (2014) 9:e91821. doi: 10.1371/journal.pone.0091821

139. Murray SG, Schmajuk G, Trupin L, Gensler L, Katz PP, Yelin EH, et al. National lupus hospitalization trends reveal rising rates of herpes zoster and declines in pneumocystis pneumonia. PLOS ONE (2016) 11:e0144918. doi: 10.1371/journal.pone.0144918

140. Turesson C, Matteson EL. Malignancy as a comorbidity in rheumatic diseases. Rheumatology (2013) 52:5-14. doi: 10.1093/rheumatology/kes189

141. Choi MY, Flood K, Bernatsky S, Ramsey-Goldman R, Clarke AE. A review on SLE and malignancy. Best Pract Res Clin Rheumatol. (2017) 31:373-96. doi: 10.1016/j.berh.2017.09.013

142. Buskila D, Press J, Abu-Shakra M. Fibromyalgia in systemic lupus erythematosus: prevalence and clinical implications. Clin Rev Allergy Immunol. (2003) 25:25-8. doi: 10.1385/CRIAI:25:1:25

143. Haliloglu S, Carlioglu A, Akdeniz D, Karaaslan Y, Kosar A. Fibromyalgia in patients with other rheumatic diseases: prevalence and relationship with disease activity. Rheumatol Int. (2014) 34:1275-80. doi: 10.1007/s00296-014-2972-8

144. Zhang L, Fu T, Yin R, Zhang Q, Shen B. Prevalence of depression and anxiety in systemic lupus erythematosus: a systematic review and meta-analysis. BMC Psychiatry (2017) 17:70. doi: 10.1186/s12888-017-1234-1

145. Bertsias G, Ioannidis JP, Boletis J, Bombardieri S, Cervera R, Dostal C, et al. EULAR recommendations for the management of systemic lupus erythematosus. Report of a Task Force of the EULAR Standing Committee for International Clinical Studies Including Therapeutics. Ann Rheum Dis. (2008) 67:195-205. doi: 10.1136/ard.2007.070367

146. Perricone C, Versini M, Ben-Ami D, Gertel S, Watad A, Segel MJ, et al. Smoke and autoimmunity: the fire behind the disease. Autoimmu Rev. (2016) 15:354-74. doi: 10.1016/j.autrev.2016.01.001

147. Costenbader KH, Karlson EW. Cigarette smoking and systemic lupus erythematosus: a smoking gun? Autoimmunity (2005) 38:541-7. doi: 10.1080/08916930500285758

148. Jiang F, Li S, Jia C. Smoking and the risk of systemic lupus erythematosus: an updated systematic review and cumulative meta-analysis. Clin Rheumatol. (2015) 34:1885-92. doi: 10.1007/s10067-015-3008-9

149. Versini M, Tiosano S, Comaneshter D, Shoenfeld Y, Cohen AD, Amital H. Smoking and obesity in systemic lupus erythematosus: a cross-sectional study. Eur J Clin Invest. (2017) 47:422-7. doi: 10.1111/eci.12757

150. Takvorian SU, Merola JF, Costenbader KH. Cigarette smoking, alcohol consumption and risk of systemic lupus erythematosus. Lupus (2014) 23:537-44. doi: 10.1177/0961203313501400

151. Barbhaiya M, Tedeschi SK, Lu B, Malspeis S, Kreps D, Sparks JA, et al. Cigarette smoking and the risk of systemic lupus erythematosus, overall and by anti-double stranded DNA antibody subtype, in the Nurses' Health Study cohorts. Ann Rheum Dis. (2018) 77:196-202. doi: 10.1136/annrheumdis-2017-211675

152. Kiyohara C, Washio M, Horiuchi T, Asami T, Ide S, Atsumi T, et al. Cigarette smoking, alcohol consumption, and risk of systemic lupus erythematosus: a case-control study in a Japanese population. J Rheumatol. (2012) 39:1363-70. doi: 10.3899/jrheum.111609

153. Rodriguez Huerta MD, Trujillo-Martin MM, Rua-Figueroa I, Cuellar-Pompa L, Quiros-Lopez R, Serrano-Aguilar P, et al. Healthy lifestyle habits for patients with systemic lupus erythematosus: a systemic review. Semin Arthritis Rheum. (2016) 45:463-70. doi: 10.1016/j.semarthrit.2015.09.003

154. Parodis I, Sjowall C, Jonsen A, Ramskold D, Zickert A, Frodlund M, et al. Smoking and pre-existing organ damage reduce the efficacy of 
belimumab in systemic lupus erythematosus. Autoimmu Rev. (2017) 16:34351. doi: 10.1016/j.autrev.2017.02.005

155. Sharif K, Watad A, Bragazzi NL, Lichtbroun M, Amital H, Shoenfeld Y. Physical activity and autoimmune diseases: Get moving and manage the disease. Autoimmu. Rev. (2018) 17:53-72. doi: 10.1016/j.autrev.2017.11.010

156. Esposito K, Pontillo A, Di Palo C, Giugliano G, Masella M, Marfella R, et al. Effect of weight loss and lifestyle changes on vascular inflammatory markers in obese women: a randomized trial. JAMA (2003) 289:1799-804. doi: 10.1001/jama.289.14.1799

157. Katz P, Yazdany J, Julian L, Trupin L, Margaretten M, Yelin E, et al. Impact of obesity on functioning among women with systemic lupus erythematosus. Arthritis Care Res. (2011) 63:1357-64. doi: 10.1002/acr.20526

158. Legge A, Blanchard C, Hanly JG. Physical activity and sedentary behavior in patients with systemic lupus erythematosus and rheumatoid arthritis. Open Access Rheumatol. (2017) 9:191-200. doi: 10.2147/OARRR.S14

159. Grabar S, Groh M, Bahuaud M, Le Guern V, Costedoat-Chalumeau N, Mathian A, et al. Pneumococcal vaccination in patients with systemic lupus erythematosus: A multicenter placebo-controlled randomized double-blind study. Vaccine (2017) 35:4877-85. doi: 10.1016/j.vaccine.2017.07.094

160. Chang CC, Chang YS, Chen WS, Chen YH, Chen JH. Effects of annual influenza vaccination on morbidity and mortality in patients with Systemic Lupus Erythematosus: a Nationwide Cohort Study. Sci Rep. (2016) 6:37817. doi: $10.1038 /$ srep37817

161. Bragazzi NL, Watad A, Sharif K, Adawi M, Aljadeff G, Amital H, et al. Advances in our understanding of immunization and vaccines for patients with systemic lupus erythematosus. Expert Rev Clin Immunol. (2017) 13:939-49. doi: 10.1080/1744666X.2017.1361321

162. Yun H, Yang S, Chen L, Xie F, Winthrop K, Baddley JW, et al. Risk of herpes zoster in autoimmune and inflammatory diseases: implications for vaccination. Arthritis Rheumatol. (2016) 68:2328-37. doi: 10.1002/art.39670

163. Grein IH, Groot N, Lacerda MI, Wulffraat N, Pileggi G. HPV infection and vaccination in Systemic Lupus Erythematosus patients: what we really should know. Pediatr Rheumatol Online J. (2016) 14:12. doi: 10.1186/s12969-016-0072-x

164. Apostolopoulos D, Morand EF. It hasn't gone away: the problem of glucocorticoid use in lupus remains. Rheumatology (2017) 56 (suppl. 1):i11422. doi: 10.1093/rheumatology/kew406

165. Morand EF, Mosca M. Treat to target, remission and low disease activity in SLE. Best Pract Res Clin Rheumatol. (2017) 31:342-50. doi: 10.1016/j.berh.2017.09.009

166. van Vollenhoven RF, Mosca M, Bertsias G, Isenberg D, Kuhn A, Lerstrom $\mathrm{K}$, et al. Treat-to-target in systemic lupus erythematosus: recommendations from an international task force. Ann Rheum Dis. (2014) 73:958-67. doi: 10.1136/annrheumdis-2013-205139

167. Marmor MF, Kellner U, Lai TY, Melles RB, Mieler WF, American Academy of Ophthalmology. Recommendations on Screening for Chloroquine and Hydroxychloroquine Retinopathy (2016 Revision). Ophthalmology (2016) 123:1386-94. doi: 10.1016/j.ophtha.2016.01.058

168. Marcondes F, Scheinberg M. Belimumab in the treatment of systemic lupus erythematous: an evidence based review of its place in therapy. Autoimmu Rev. (2018) 17:103-7. doi: 10.1016/j.autrev.2017.11.013
169. Touma Z, Sayani A, Pineau CA, Fortin I, Matsos M, Ecker GA, et al. Belimumab use, clinical outcomes and glucocorticoid reduction in patients with systemic lupus erythematosus receiving belimumab in clinical practice settings: results from the OBSErve Canada Study. Rheumatol Int. (2017) 37:865-73. doi: 10.1007/s00296-017-3682-9

170. McLaurin EY, Holliday SL, Williams P, Brey RL. Predictors of cognitive dysfunction in patients with systemic lupus erythematosus. Neurology (2005) 64:297-303. doi: 10.1212/01.WNL.0000149640.78684.EA

171. Szabo MZ, Szodoray P, Kiss E. Dyslipidemia in systemic lupus erythematosus. Immunol Res. (2017) 65:543-50. doi: 10.1007/s12026-016-8892-9

172. Bertsias GK, Tektonidou M, Amoura Z, Aringer M, Bajema I, Berden $\mathrm{JH}$, et al. Joint European League Against Rheumatism and European Renal Association-European Dialysis and Transplant Association (EULAR/ERA-EDTA) recommendations for the management of adult and paediatric lupus nephritis. Ann Rheum Dis. (2012) 71:1771-82. doi: 10.1136/annrheumdis-2012-201940

173. Ruiz-Irastorza G, Cuadrado MJ, Ruiz-Arruza I, Brey R, Crowther M, Derksen $\mathrm{R}$, et al. Evidence-based recommendations for the prevention and long-term management of thrombosis in antiphospholipid antibody-positive patients: report of a task force at the 13th International Congress on antiphospholipid antibodies. Lupus (2011) 20:206-18. doi: 10.1177/0961203310 395803

174. Blaauw AA, Schuwirth LW, van der Vleuten CP, Smits F, van der Linden S. Assessing clinical competence: recognition of case descriptions of rheumatic diseases by general practitioners. Br J Rheumatol. (1995) 34:375-9.

175. Urowitz MB, Kagal A, Rahman P, Gladman DD. Role of specialty care in the management of patients with systemic lupus erythematosus. J Rheumatol. (2002) 29:1207-10.

176. Rees F, Doherty M, Lanyon P, Davenport G, Riley RD, Zhang W, et al. Early clinical features in systemic lupus erythematosus: can they be used to achieve earlier diagnosis? A risk prediction model. Arthritis Care Res. (2017) 69:833-41. doi: 10.1002/acr.23021

177. Molina MJ, Mayor AM, Franco AE, Morell CA, Lopez MA, Vila LM. Utilization of health services and prescription patterns among lupus patients followed by primary care physicians and rheumatologists in Puerto Rico. Ethnicity Dis. (2008) 18 (2 Suppl. 2):S2-205-10.

178. Wilhelmus S, Bajema IM, Bertsias GK, Boumpas DT, Gordon C, Lightstone L, et al. Lupus nephritis management guidelines compared. Nephrol Dial Transpl. (2016) 31:904-13. doi: 10.1093/ndt/gfv102

Conflict of Interest Statement: The authors declare that the research was conducted in the absence of any commercial or financial relationships that could be construed as a potential conflict of interest.

Copyright $\odot 2018$ Gergianaki and Bertsias. This is an open-access article distributed under the terms of the Creative Commons Attribution License (CC BY). The use, distribution or reproduction in other forums is permitted, provided the original author(s) and the copyright owner are credited and that the original publication in this journal is cited, in accordance with accepted academic practice. No use, distribution or reproduction is permitted which does not comply with these terms. 